\title{
Whole-grain food
}

Healthgrain Forum

\section{Source}

Alastair B Ross, Jan-Willem van der Kamp, Roberto King, Kim-Anne Lê, Heddie Mejborn, Chris J Seal, and Frank Thielecke, on behalf of the Healthgrain Forum. (2017). Perspective:

A Definition for Whole-Grain Food Products-Recommendations from the Healthgrain Forum. Advances in Nutrition (AN/Adv Nutr), vol. 8(4):525-531 .

A whole-grain food is one for which the product is made with $\geq 30 \%$ whole-grain ing redients on a dry-weight basis and more whole-grain ingredients than refined-grain ing redients. 